\title{
SUSTAINABLE LAND USE EVALUATION BASED ON PRESERVATIVE APPROACH
}

\author{
S. Khademi ${ }^{1 *}$, M. Norouzi ${ }^{2}$, M. Hashemi ${ }^{3}$ \\ ${ }^{1}$ Dept. of Geography, Kharazmi University, Tehran, Iran - somaye.khademi@gmail.com \\ ${ }^{2}$ Dept. of Geography, Tarbiat Modares University, Tehran, Iran - norouzi.m60@ gmail.com \\ ${ }^{3}$ Dept. of Architecture and Urbanism, University of Tehran, Iran - mahsa.hashemi@ut.ac.ir
}

Commission VI, WG VI/4

KEY WORDS: Urban Sustainable Development, Land-use Evaluation, Sustainability Indexes, Historical Heritages, City of Susa

\begin{abstract}
:
Determining the manner of land-use and the spatial structure of cities on the one hand, and the economic value of each piece of land on the other hand, land-use planning is always considered as the main part of urban planning. In this regard, emphasizing the efficient use of land, the sustainable development approach has presented a new perspective on urban planning and consequently on its most important pillar, i.e. land-use planning. In order to evaluate urban land-use, it has been attempted in this paper to select the most significant indicators affecting urban land-use and matching sustainable development indicators. Due to the significance of preserving ancient monuments and the surroundings as one of the main pillars of achieving sustainability, in this research, sustainability indicators have been selected emphasizing the preservation of ancient monuments and historical observance of the city of Susa as one of the historical cities of Iran. It has also been attempted to integrate these criteria with other land-use sustainability indicators. For this purpose, Kernel Density Estimation (KDE) and the AHP model have been used for providing maps displaying spatial density and combining layers as well as providing final maps respectively. Moreover, the rating of sustainability will be studied in different districts of the city of Shush so as to evaluate the status of land sustainability in different parts of the city. The results of the study show that different neighborhoods of Shush do not have the same sustainability in land-use such that neighborhoods located in the eastern half of the city, i.e. the new neighborhoods, have a higher sustainability than those of the western half. It seems that the allocation of a high percentage of these areas to arid lands and historical areas is one of the main reasons for their sustainability.
\end{abstract}

\section{INTRODUCTION}

The sustainability of the planet is threatened by climate change and global warming caused by greenhouse gas emissions. In fact, cities account for more than $70 \%$ of this complication (Kam Ng, 2016; Baabou et al, 2017). In 2014, about 54 percent of the world's population lived in urban areas, and this figure would increase by about 66 percent by 2050 , indicating an increase of about two billion and 400 million urban inhabitants (United Nations, 2015, p. 23). Such growth requires more environmentally friendly approaches in urban planning and development. Legitimizing this new approach has prompted researchers to further work on sustainable development issues. This potential approach is one of the key pillars of the research on the concept of sustainable land use, especially in the area of applied models and the evaluation of indicators (Ogu, 1999; Zhang et al, 2011; Chang and Chiu, 2012; Kashefidust and Hajinejad, 2015; Qian et al, 2015).

Undoubtedly, the issue of how to use land for various urban activities has become one of the main economic, social, political and environmental issues of today's society, and how to balance the use of the environment and preventing disturbances in the social environment of cities has always been a matter for policy makers and decision-makers for urban affairs. The land is always considered as one of the major sources of the city. As its use affect the relationship between all urban activities. For example, the effectiveness of infrastructure systems is strongly influenced by the issues of development density, the development plan and the combination of land use and form and size of parts (European Commission, 2002: 54). Therefore, the necessity of studying the ecological and biological characteristics of the city and its relation to land use and proper prospective within the framework of urban development plans not only arrange the space in the present time but also has a huge impact on the expansion, balanced development and sustainable development of the city in the future.

With the proliferation of sustainable urban development theory, the issue of planning for historical and cultural works has entered into development planning, especially urban planning, as part of social and cultural sustainability. However, the lack of systematic assessment methodologies for addressing the gap between urban development and the protection of cultural and historical heritage has been mentioned in various academic studies (Bond et al, 2004; Guzmán et al, 2017). However, in many international studies and presentations, cultural and historical heritage is referred to as one of the main themes of sustainable development of cities and local communities (Bond et al, 2004; Tweed and Sutherland, 2007; Al-hagla, 2010; Guzmán et al, 2017). In the Middle East, Nabil Mohareb's research is considered to be a worthwhile study on providing appropriate indicators for assessing the sustainability of land use in Arab cities. He, by examining the various factors affecting the sustainable development of urban land use and their method of measuring them, describes these principles in three categories: social, economic, and environmental indicators. To this end, he analyses the concepts of sustainable urban land use, introduces the quality indicators for land use

\footnotetext{
* Corresponding author
} 
sustainability, and then, according to them, he selects quantitative indicators and evaluation variables and appropriate tools for analysing the sustainability indicators of urban land use. His emphasis in social indicators category is on indicators of the protection of cultural and historical heritage, social justice and urban identity (Mohareb, 2009). Another example of the measures taken is the Brazil's Sustainable Urban Development Kit. In this plan, seven important creative steps have been taken to achieve sustainability that one of these seven important actions is the protection of the city's cultural and historical areas (World Bank, 2010: 170).

In most of these studies, making linkage between historical and cultural values with the development of the city's physicalspatial development is considered to be the most important axis of sustainable urban development, which has not yet found its worthy place in Iran. (Mahdizade, 2005) By expressing duality in the present-day cities of Iran, due to the existence of historical textures and buildings on one hand, and on the other hand, the growing growth of cities and their social and spatial changes, discusses the dual functions of historical monumentsconservation and use- and introduces sustainable development as an appropriate approach to solve this conflict. Among the historical cities of Iran is the city of Susa. The city of Susa was founded as one of the oldest cities in the world, around $4,000,000 \mathrm{BC}$, as the religious centre of the inhabitants of its neighbourhoods. It has historical monuments from different periods such as Ilam, Achaemenid, and Islam to Qajar; that the historical arena of these works is now in the city. In this way, it is imperative that a sustainable urban development program in this historic city be accompanied by criteria for the protection of historical values. On the other hand, given that the land use planning in this city, like other Iranian cities, is based on the criteria set out in comprehensive -rational schemes, therefore, the present study aims to evaluate the land use in the city of Susa based on the principles of sustainable urban development and to consider the impact of conservation measures on historical monuments. In this way, indicators were considered that would be in line with the criteria provided by the Cultural Heritage Organization to protect the historical monuments of the city of Susa, so that, based on this, a suitable model of urban development could be achieved.

\section{LITERATURE REVIEW}

\subsection{Sustainable Development: Definitions and Dimensions}

The emergence of the concept of sustainable development since the early 1970s is the result of responding to growing concerns about the destructive effects of development on the environment. This concept was addressed by the United Nations as a topic of the last decade of the twentieth century and was designated as Agenda 21 at the international, regional and local levels (Roseland, 1997; Finco and Nijkamp, 2001). Sustainable development has emerged as a new paradigm of development, integrated economic growth, improved social conditions and environmental protection, in which these factors are mutually supportive to achieve long-term development. Therefore, sustainable development emphasizes a comprehensive and participatory approach to policy and implementation, the mobilization of public and private resources for development, the use of knowledge, skills and the power of all social groups (Jiboye \& Omoniyi, 2010). In relation to this concept, various definitions have been made and according to the approaches that have developed for sustainable development, the type of definitions, the definition of the type of purpose and its principles have also been somewhat varied. Perhaps the best definition of sustainable development is the report of the World Commission on Environment and Development, Which considers sustainable development to be a development that meets the needs of the present generation without sacrificing future generations' capabilities to meet their needs (WCED, 1987). Similar definitions have been made by international institutions and individuals to illustrate this concept; one of the definitions is the Britain National Housing Agency which provides sustainable development as a tool to ensure a better quality of life for all individuals, including the present generation and future generations (Jiboye \& Ogunshakin, 2011). From the perspective of (Jiboye, 2011; Sofeska, 2016), sustainable development is a socio-ecological process that simultaneously takes into account the needs of the inhabitants of the planet and the preservation of the natural environment. Nevertheless, (MÜLLER-EIE \& BJØRNØ, 2017; Yang et al, 2017), consider sustainable urban development as an essential element of urban planning and a complex concept which consists of several sets and sub-assemblies of concepts, levels, strategies and actors, both in the local and global dimension, whose study requires the participation of different sciences. That is why some researchers consider the operational definition of sustainable development to be controversial. However, according to (Gilmour et al, 2011), in general, the real challenge in understanding how to define the definition of sustainability is accepted in its applied text, which can be interpreted as sustainability operation. In this regard, (Roseland, 1998: 77) suggests that sustainable development should be conceptualized as doing development in a different way. So that by pursuing economic activities, in terms of socially and environmentally sustainable, it sought human comfort and wellbeing. Although there are still disagreements about the meaning of sustainable development, many definitions agree on sustainable development seeking to achieve economic, social and environmental goals simultaneously (WCED, 1987; Campbell, 1996; Finco and Nijkamp, 2001; Haughton and Hunter, 2003; Alpopi, Manole \& Colesca, 2011; Jepson and Haines, 2014; Shaker and Sirodoev, 2016; Yang et al, 2017).

\subsection{Using Sustainability in Land Use Planning}

One of the goals of the sustainable development of the Third Millennium, which was drawn up by the United Nations (UN, 2015 ) with the horizon of 2030 , is "Make cities and human settlements inclusive, safe, resilient and sustainable".

This goal is as follows:

"provide universal access to safe, inclusive and accessible, green and public spaces, in particular for women and children, older persons and persons with disabilities"

This goal demonstrates the importance of appropriate land distribution and planning for the accessibility of urban areas to various citizens. The view of sustainable development, land and space is not only an element to meet the economic and physical needs of the city but is the mainstay of all the activities of citizens and the means necessary to fulfil human demands and aspirations. Therefore, the use of urban land plays a major role in meeting the needs of citizens, the quality of the environment, the health and comfort of citizens, the beauty of the urban environment and, ultimately, the sustainable development of the city.

By describing the concepts of various theories, Stuart Chapin describes the concepts of land use management in three groups 
of values that should be balanced for land use planning; He, along with social and market values, mentions ecological values as the third pillar. These values express the weight that people bring to the natural systems of the earth and express land use as a potential environmental threat that must be reduced (Chapin, 1995: 43-51).

In recent years, land use planning has been widely considered as an appropriate tool for implementing sustainable development (Roy, 2009; UN-Habitat, 2009; Zhang et al, 2011; Baffour Awuah et al., 2014; Kashefidust and Hajinejad, 2015; Sang et al, 2016). Most of these studies show that land use plays a vital and crucial role. Land use at the city level can have environmental benefits to help the well-being and quality of life of citizens, especially in developing countries. Because the results of population, economics, nature and other studies are reflected in the land use, thus obtaining a physical-spatial manifestation, and, on the other hand, the result of the urban planning planner is the land use map.

In fact, the sustainable city refers to an ideal structure built up by sustainable land use and urban design principles (Yigitcanlar and Dizdaroglu, 2015). This means the changes that take place in land use and in the levels of concentration , while meeting the city's needs for housing, transportation, leisure and food, give the city a habitable and living environment (clean air, safe drinking water, land and surface water and groundwater, pollution free, etc.) ,a city which is economically sustainable (urban economy with technical and industrial changes to maintain its basic occupations and provide adequate housing to the extent affordable to its inhabitants with a fair per capita tax burden) and a city which is socially closed (land use patterns promote social solidarity and citizens' sense of belonging to the city's heritage) (Mukomo, 1996).

\section{MATERIALS AND METHODS}

\subsection{Land Use Indexes}

This research is descriptive-analytical in terms of research method, and according to the nature of research, is an applied research. The data and information included are the data in the last census of population and housing in Iran, maps of the comprehensive review plan of Susa city and proposed maps of the cultural heritage organization of Susa city about the scope of the historical city of Susa and the terms and conditions provided. For analysing the data, after analysing the theoretical framework, the indices and the basic and influential variables in the subject matter, namely sustainable land use and cultural heritage ,were identified (Table 1).

Table 1. Land use indexes of Susa city from development perspective

\begin{tabular}{|c|c|c|c|c|c|}
\hline Index & Sub-index & Measurement Unit & Spatial Scale & $\begin{array}{l}\text { Analyzing } \\
\text { Method }\end{array}$ & Database \\
\hline \multirow{6}{*}{ 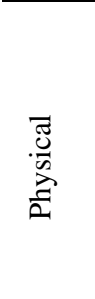 } & Age of building & Year & City & GIS & Review of master plan \\
\hline & Materials & Percent in land uses & Neighborhood & GIS & Review of master plan \\
\hline & Numbers of floors & Percent in land uses & Neighborhood & GIS & Review of master plan \\
\hline & Building intensity & Area in hectare & City & GIS \& KDE & Review of master plan \\
\hline & Residential coverage & Person in hectare & City & GIS \& KDE & Review of master plan \\
\hline & Safety and quality & Percent in land uses & Neighborhood & GIS & Review of master plan \\
\hline \multirow{3}{*}{ 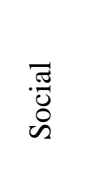 } & Population density & Person in hectare & City & GIS \& KDE & Population and housing census \\
\hline & Household density & Numbers in hectare & City & GIS \& KDE & Population and housing census \\
\hline & Residential per capita & $\begin{array}{l}\text { Square meter for each } \\
\text { person }\end{array}$ & Neighborhood & GIS & Population and housing census \\
\hline \multirow{3}{*}{ 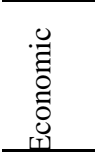 } & Land price & $(\text { IRR })^{\mathrm{a}}$ for square meter & Neighborhood & GIS & Review of master plan \\
\hline & Occupational density & Person in hectare & City & GIS \& KDE & Population and housing census \\
\hline & Unemployment density & Person in hectare & City & GIS \& KDE & Population and housing census \\
\hline \multirow{3}{*}{ 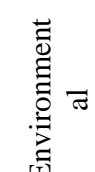 } & Distance from river & Meter & City & GIS & Review of master plan \\
\hline & $\begin{array}{l}\text { Distance from green } \\
\text { space }\end{array}$ & Meter & City & GIS & Review of master plan \\
\hline & Distance from industries & Meter & City & GIS & Review of master plan \\
\hline
\end{tabular}

${ }^{\mathrm{a}}$ 1US\$ IRR 10000 (December 2018)

\subsection{Research Model}

For the analysis of data indicating the density or density of the index in the space or range studied, the kernel density estimation (KDE) is used and the final composition of the layers are derived from the Hierarchical Analytic Analyser (AHP) and Modelling in the Software Environment (Arc GIS) and the land use pattern is analysed according to it.

\subsubsection{Kernal Density Estimation (KDE)}

Using the Kernel Density Estimation (also called KDE) estimates the position of the points in space in a continuous density function in the study area, In addition, it allows an intuitive vista through a three-dimensional surface, not by limiting a point, but by displaying changes in the density of any point within the studied range. This method of dot-point data modelling creates a lattice structure that fully covers the scope of the study. Each raster cell contains the property of a quantity and density in accordance with the distribution of quantities (points). In general, KDE is used for general applications in the Earth sciences. Recently, however, applications in the field of social sciences have been the same as surveying population 
density and distribution or clustering of human activities in space. The kernel method is a combination of a set of threedimensional functions that show the weight of each point within their penetration region according to their distance from the point where the density is estimated.

However, the question is that what is the best scale for geographic clusters that should be determined? What is the correct level of aggregation (density)? What neighbourhood, core, or kernel or window size search (space) should be used? This is an important issue, since it has a significant impact on the softness and smoothing used on the data. Spatial estimation techniques are inherently spatial statistics because outputs are not at all independent of the geographic scale of analysis (window size or search space) (Borruso, 2008; Murgante et al, 2009; Timothee et al, 2010).

\subsubsection{Analytic Hierarchy Process (AHP)}

Hierarchy analysis process is one of the most comprehensive systems designed for decision making with multiple criteria. It allows the formulation of the problem to be hierarchical (Gharagozlu and Barzegar, 2008). The process of hierarchical analysis relies on judgments (Whitaker, 2007). In addition, its use does not require math, it is easy to understand, and can effectively control both quantitative and qualitative data (Cengiz, et al, 2003). The first step in the hierarchical analysis process is to create a hierarchical structure of the subject under investigation in which the objectives, criteria, options, and the relationship between them are shown. The next four steps in the hierarchical analysis process are to compute the coefficient of significance of the criteria and sub criteria, calculate the importance coefficient of options, calculate the final scores of options, and examine the logical compatibility of judgments (Zebardast, 2001). In this research, Expert choice software was used to weigh the criteria.

\section{LAND USE IN SUSA CITY}

Table 2 shows the land use of the city of Susa. As shown in this table, wastelands have the largest area in the city of Susa. These lands make up about 28 percent of the city's total area. Following the wastelands, the historic site of the city of Susa occupies about 21 percent of the area of the city of Susa. By adding these two, about 50 percent of the lands of the city of Susa are occupied by historic and wastelands. One of the reasons for the high area of the wastelands in the city of Susa is the existence of historical boundaries and cultural heritage laws in relation to construction. Residential use with 19 percent and transportation network with 17 percent of the total area of the city after the wastelands and the historical places have the largest share of the uses of the city of Susa. But in terms of blocks, residential uses $(77.75 \%)$, commercial $(11.7 \%)$ and wastelands $(5.7 \%)$ have the largest number of blocks. Map Number (1) illustrates the distribution of the land uses in the present state of the city of Susa. As it is illustrated, the city of Susa has a scattered developmental area and is surrounded by agricultural lands where confronts the physical expansion of the city.

Table 2. The present situation of and use in Susa city

\begin{tabular}{|c|c|c|c|c|}
\hline Land Use & $\begin{array}{l}\text { Area } \\
\text { (Hectare) }\end{array}$ & $\begin{array}{l}\text { Percent } \\
\text { (Area) }\end{array}$ & Numbers & $\begin{array}{l}\text { Percent } \\
\text { (Numbers) }\end{array}$ \\
\hline Official & 24.14 & 1.535 & 49 & 0.01 \\
\hline Wastelands & 438.40 & 27.874 & 1000 & 0.09 \\
\hline Military & 8.31 & 0.528 & 14 & 0.01 \\
\hline Educational & 25.71 & 1.635 & 66 & 0.15 \\
\hline Gardening & 4.76 & 0.303 & 6 & 0.01 \\
\hline $\begin{array}{l}\text { Utilities and } \\
\text { Facilities }\end{array}$ & 14.26 & 0.906 & 17 & 0.05 \\
\hline $\begin{array}{l}\text { Business } \\
\text { Districts }\end{array}$ & 9.27 & 0.589 & 2046 & 0.03 \\
\hline Frontages & 31.14 & 1.980 & 30 & 0.03 \\
\hline Warehouses & 5.65 & 0.359 & 47 & 0.92 \\
\hline Social Services & 0.45 & 0.029 & 4 & 0.02 \\
\hline Sanitary & 0.03 & 0.002 & 1 & 1.89 \\
\hline $\begin{array}{l}\text { Tourism } \\
\text { Services }\end{array}$ & 0.14 & 0.009 & 2 & 0.22 \\
\hline Medical & 7.30 & 0.464 & 16 & 77.75 \\
\hline $\begin{array}{l}\text { Animal } \\
\text { Husbandry }\end{array}$ & 0.54 & 0.034 & 2 & 0.05 \\
\hline River & 24.87 & 1.581 & 27 & 100 \\
\hline $\begin{array}{l}\text { Transportation } \\
\text { Network } \\
\end{array}$ & 275.27 & 17.502 & 1 & 0.01 \\
\hline Industrial & 1.42 & 0.091 & 9 & 0.09 \\
\hline Workhouse & 1.10 & 0.070 & 6 & 0.01 \\
\hline Recreational & 0.64 & 0.041 & 5 & 0.15 \\
\hline Green Spaces & 43.47 & 2.764 & 161 & 0.01 \\
\hline $\begin{array}{l}\text { Historical } \\
\text { Places }\end{array}$ & 327.70 & 20.836 & 3 & 0.05 \\
\hline Mixed Uses & 5.41 & 0.344 & 331 & 0.03 \\
\hline Religious & 3.46 & 0.220 & 38 & 0.03 \\
\hline Residential & 298.45 & 18.976 & 13595 & 0.92 \\
\hline Sports Centres & 20.87 & 1.327 & 9 & 0.02 \\
\hline Overall & 1572.76 & 100 & 17485 & 1.89 \\
\hline
\end{tabular}




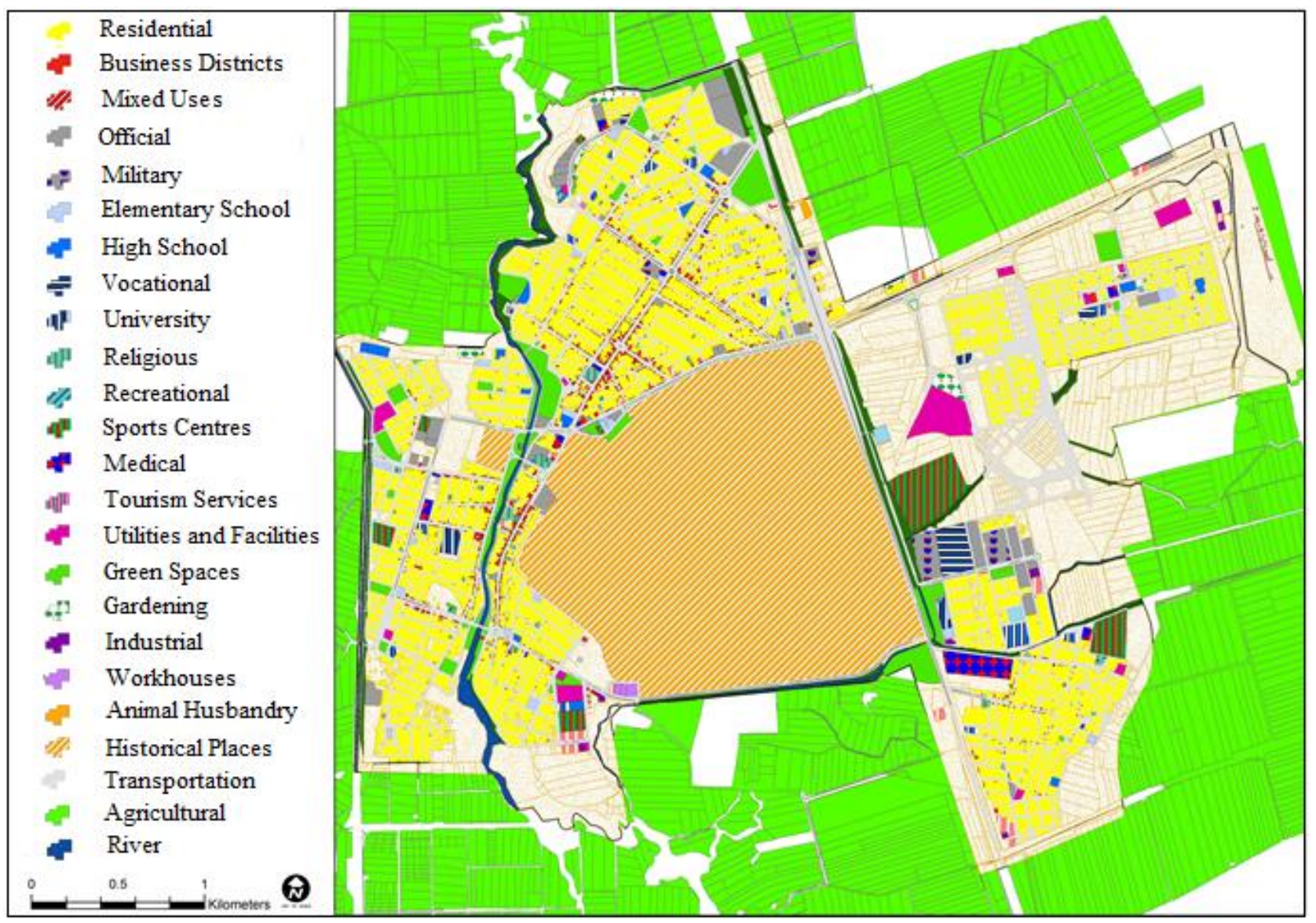

Figure. 1 The Land Uses in Susa City (Iran Amayesh, 2011)

\section{WEIGHING, MEASURING AND FINAL COMPOSITION OF THE LAYERS AND THE DATA ANALYZED}

In order to protect the historical monuments of Susa city to combine different layers and provide a picture of the land use stability in different parts of the city of Susa, the layers were weighed and measured in 5 levels from very desirable to very undesirable. Layers weighed according to cultural heritage more desirable situation. In the construction density layer, due to the fact that the increase of the construction density increases the built-in level and ultimately increases the number of floors and given that based on the existing evidence, the current city of Susa is built on an ancient and historical arena, so The emphasis is on reducing the density of buildings to prevent the destruction of underground works as well as the privacy of the discovered works. In the layers of population density and households, the emphasis has been on reducing and consolidating the population within the city of Susa, which one of the main reasons for this can be to prevent further destruction of the ancient layers due to the passage of urban facilities and the prevention of construction in the historical area of Susa. In the price of land layer, despite the fact that land prices are an economic value, in developing countries, rising land prices have led to stockpiles on the ground and the expansion of the city's boundaries and the destruction of agricultural lands and also the increase in construction in cities due to the encouragement of municipalities. Therefore, in this case, we emphasize land price cushioning to prevent its consequences. Also, given the fact that the industries are causing environmental pollution and destruction of historical monuments in the long run, the emphasis is on increasing distance. Other layers have been selected with emphasis on sustainable urban development indicators that are not in conflict with the conservation of historical monuments and cultural heritage laws. After applying the weights given in the Expert Choice software, Arc GIS software was used for final composition of the layers. You can see the weights and measurements of the layers in Table 3. Also, map 2 shows the final composition of the layers in different locations based on the desirable condition of loneliness and the sustainability of land use.

Table 3. Measurement scale and final weighing of spaces

\begin{tabular}{|c|c|c|c|c|c|c|c|}
\hline \multirow{2}{*}{$\begin{array}{c}\text { Inde } \\
\quad x\end{array}$} & \multirow{2}{*}{ Sub-indexes } & \multicolumn{5}{|c|}{ Measurement Scale } & \multirow{2}{*}{$\begin{array}{l}\text { Weight } \\
\text { in AHP }\end{array}$} \\
\hline & & Low & Medium-Low & Medium & Medium-High & High & \\
\hline \multirow{4}{*}{ 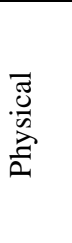 } & Age of building (year) & Without structure & More than 30 & $10-30$ & Less than 10 & In building & 4 \\
\hline & Materials & Clay and wood & Seminal block & Brick and Iron & Steel skeleton & $\begin{array}{l}\text { Concrete } \\
\text { skeleton }\end{array}$ & 5 \\
\hline & Numbers of floors* & More than 3 & 3 floors & 2 floors & 1 floors & $\begin{array}{l}\text { Without } \\
\text { structure }\end{array}$ & 9 \\
\hline & Coverage density & 41 and more & $30-40$ & $20-30$ & $10-20$ & $0-10$ & 7 \\
\hline
\end{tabular}


The International Archives of the Photogrammetry, Remote Sensing and Spatial Information Sciences, Volume XLII-2/W11, 2019 GEORES 2019 - 2nd International Conference of Geomatics and Restoration, 8-10 May 2019, Milan, Italy

\begin{tabular}{|c|c|c|c|c|c|c|c|}
\hline & (percent)* & & & & & & \\
\hline & $\begin{array}{l}\text { Residential density (in } \\
\text { hectare) }\end{array}$ & 53 and more & $39-52$ & $26-39$ & $13-26$ & $0-13$ & 7 \\
\hline & Housing quality & Worn out & abandoned & In demolition & Usable & New or renew & 5 \\
\hline \multirow{3}{*}{ 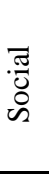 } & Population density* & 201 and more & $151-200$ & $101-150$ & $51-100$ & $0-50$ & 7 \\
\hline & Household density* & 41 and more & $31-40$ & $21-30$ & $11-20$ & $0-10$ & 7 \\
\hline & $\begin{array}{l}\text { Residential per Capita } \\
\text { (square meter) }\end{array}$ & $0-20$ & $21-40$ & $41-60$ & $61-80$ & 81 and more & 7 \\
\hline \multirow{3}{*}{ 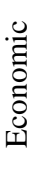 } & $\begin{array}{l}\text { Land price ((IRR)** for } \\
\text { square meter) }\end{array}$ & 800 and more & $700-800$ & $600-700$ & $500-600$ & 5010 and less & 9 \\
\hline & Occupational density & $0-10$ & $11-20$ & $21-30$ & $31-40$ & 41 and more & 9 \\
\hline & Unemployment density & $0-5$ & $6-10$ & $11-15$ & $16-20$ & 21 and more & 6 \\
\hline \multirow{3}{*}{ 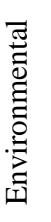 } & $\begin{array}{l}\text { Distance from river } \\
\text { (Meter)* }\end{array}$ & $0-20$ & $21-60$ & $61-80$ & $81-100$ & 101 and more & 5 \\
\hline & $\begin{array}{l}\text { Distance from green } \\
\text { space (Meter) }\end{array}$ & More than 500 & $400-500$ & $300-400$ & $200-300$ & Less than 200 & 6 \\
\hline & $\begin{array}{l}\text { Distance from } \\
\text { industries (Meter)* }\end{array}$ & Less than 200 & $200-300$ & $300-400$ & $400-500$ & $\begin{array}{l}\text { More than } \\
500\end{array}$ & 5 \\
\hline
\end{tabular}

* In consideration of preservation of historical places and heritage values

** 1US\$ IRR 1000 (December 2018)

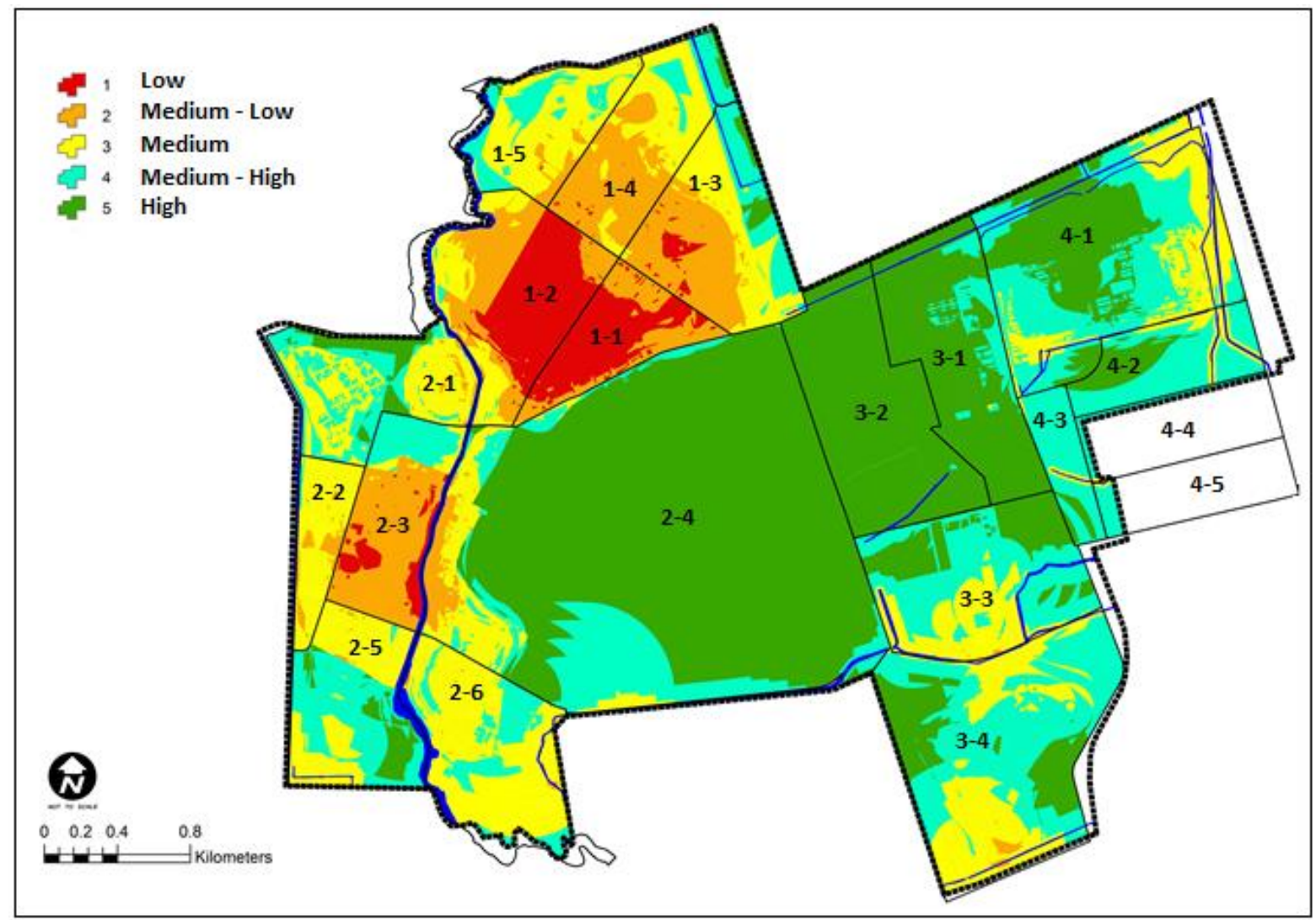

Figure 2. Final layer of land use sustainability in Susa neighbourhoods

Normalization is used to convert different indicator units into a common and comparable scale. The various normalization methods are: (a) ranking based on the indicators' performance over time; (b) standardization or z score; (c) rescaling or minmax method; (d) categorical scale (Bahadure and Kotharkar, 2015). This study uses normalization on a five-point scale. These points are: (1) Low (extremely unsustainable situation); (2) Medium-Low (not suitable but not as bad as in previous scale); (3) Medium (discrete level of sustainability); (4) Medium-High (satisfactory level of sustainability); (5) High (target level of sustainability).

Due to the combination of different layers and presentation of this map, in order to compare different neighborhoods, each of the stability states was given a score. Then by multiplying the area of each part in its sustainability score and summing it, and finally dividing the total number by area per hectare, the average stability status is obtained per hectare for each neighborhood. then, in this way it is possible to measure the level of the situation of different neighborhoods of the city. (Table 4) shows the sustainability of land use in Susa neighborhoods. Similarly, neighborhood leveling can be seen in this table.

$\begin{array}{cccc}\begin{array}{c}\text { Neighbourho } \\ \text { od Rating }\end{array} & \begin{array}{c}\text { Likert Scale } \\ \text { Medium- }\end{array} & \begin{array}{c}\text { Sustainability } \\ \text { Mean (Hectare) }\end{array} & \begin{array}{c}\text { Neighbourhood } \\ \text { Code }\end{array} \\ 15 & \text { Low } & 1.24 & 1-1\end{array}$




\begin{tabular}{|c|c|c|}
\hline 14 & $\begin{array}{l}\text { Medium- } \\
\text { Low }\end{array}$ & 1.68 \\
\hline 11 & Medium & 2.47 \\
\hline 12 & Medium & 2.46 \\
\hline 10 & Medium & 2.85 \\
\hline 7 & $\begin{array}{l}\text { Medium- } \\
\text { High }\end{array}$ & 3.13 \\
\hline 9 & Medium & 2.51 \\
\hline 13 & Medium & 2.07 \\
\hline 2 & $\begin{array}{l}\text { Medium- } \\
\text { High }\end{array}$ & 3.82 \\
\hline 6 & $\begin{array}{l}\text { Medium- } \\
\text { High }\end{array}$ & 3.2 \\
\hline 8 & Medium & 2.93 \\
\hline 1 & $\begin{array}{l}\text { Medium- } \\
\text { High }\end{array}$ & 3.98 \\
\hline 4 & $\begin{array}{l}\text { Medium- } \\
\text { High }\end{array}$ & 3.35 \\
\hline 5 & $\begin{array}{l}\text { Medium- } \\
\text { High }\end{array}$ & 3.27 \\
\hline 3 & $\begin{array}{l}\text { Medium- } \\
\text { High }\end{array}$ & 3.51 \\
\hline
\end{tabular}

Table 4. Sustainability of leveling Susa neighborhoods from historical heritage perspective

\section{CONCLUSION}

Assessment of sustainable land use requires appropriate evaluation instruments, such as land sustainable indicators. However, land quality, like the concept of sustainable land use planning of which it is a part, requires operational definitions and specific, measureable indicators if it is to be more than an attractive, conceptual phrase. Land use policy necessarily touches on every aspect of local government concern. Sustainable land use planning involves decisions on crosscutting and multi-layered issues that affect air quality, water quality, access to transportation options, economic vitality, and quality of life. It is critical to promote the creation and development of communities containing an array of types and uses of buildings and spaces to meet the diverse needs of residents' daily lives. Urban land use planning, if led by wellinformed policies based on sustainable development principles and supported by well-planned and well-managed initiatives, including investments, can help address these challenges.

In this paper, we analyzed the indicators of land use sustainability in Susa city based on sustainable urban development indicators. In order to analyze the sustainability of land use, the indicators were studied according to cultural heritage criteria and sustainable city model. In the four indexes of population density, households, structures and classes, these two opposite criteria were also considered, but due to the emphasis on the protection of historical monuments, cultural heritage standards were considered. In this way, the analysis pattern was analyzed with 15 indicators identified in four areas of macro, social, physical, environmental and economic sustainability. According to the analysis, the leveling of the neighborhoods was based on the average of the sustainability per hectare. Based on the level of the localities, we concluded that in the city of Susa, different neighborhoods do not have the same stability in land use. According to the level of the results, it was concluded that the sites 1-3, 4-2, 1-4, 3-3, 4-3 have the highest level of sustainability in land use. It seems that the allocation of a large percentage of these areas to wastelands and historic areas is one of the main reasons for their sustainability. Apart from the 4-2 neighborhood, which is located in the historic district of Susa, other neighborhoods with a high level of sustainability were added to the city limits according to the comprehensive review plan of the city of Susa. As the rural texture in those neighborhoods are quite evident. Therefore, we can see the most instability in the former district of Susa, which is within the scope of municipal services and housing and urban planning that one of the main reasons is the absence of the approved project of the historical city of Shush and the lack of coordination of the organizations mentioned in the implementation of the urban plans with the Cultural Heritage Organization can be mentioned. It can also be said that the rules of cultural heritage are in contradiction with the norms of sustainable cities in developing countries.

To improve and increase Sustainability, we offer the following solutions:

- Increasing the sense of belonging of inhabitants in order to protect cultural works;

- Increasing the city's economic activity especially in the area of sustainable tourism;

- Applying incentive and punitive policies and regulations for the removal of incompatible areas with Shavoor River historical and legal boundaries;

- Supervision and the establishment of strict rules for controlling the height of buildings;

- Define around footpaths in areas historical monuments;

\section{REFERENCES}

Al-hagla, K. S. (2010), Sustainable urban development in historical areas using the tourist trail approach: A case study of the cultural heritage and urban development (CHUD) project in Saida, Lebanon, Cities, 27(4), 234-248.

Alpopi C., Manole C. \& Colesca S. E. (2011), Assessment of the sustainable urban development level through the use of indicators of sustainability, Theoretical and Empirical Researches in Urban Management, 6(2), 78-87.

Iran Amayesh (2011), The review of Susa master plan, Urban Consulting Engineers.

Bahadure, S. \& Kotharkar, R. (2015), Assessing sustainability of mixed use neighborhoods through residents' travel behaviour and perception: The case of Nagpur, India, Sustainability, 7, 12164-12189.

Baffour Awuah, K.G., Hammond, F.N., Booth, C.A. \& Lamond, J.E. (2014), Evaluation and development of urban land use planning: Analysis from human action theory perspective, Theoretical and Empirical Researches in Urban Management, 9(2), 35-67.

Baabou, W., Grunewald, N., Ouellet-Plamondon, C., Gressot, M. \& Galli, A. (2017), The ecological footprint of Mediterranean cities: awareness creation and policy implications. Environmental Science \& Policy, 69, pp. 94-104.

Bond, A., Langstaff, L., Baxter, R., Kofoed, H-G. W. J., Lisitzin, K. \& Lundström, S. (2004), Dealing with the cultural heritage aspect of environmental impact assessment in Europe, Impact Assessment and Project Appraisal, 22(1), 37-45.

Borruso, G. (2008), Network Density Estimation: a GIS approach for analysing point patterns in a network space, Transactions in GIS, 12, 377-402.

Cambpell, S. (1996), Green cities, growing cities, just cities? Urban planning and the contradictions of sustainable development, Journal of the American Planning Association, 62(3), 296-312.

Chang, H. \& Chiu, S. (2012), Discussion on sustainable land use allocation toward the sustainable city: A practice on Linco New Town, Environmental Sciences, Proceedings of The 3rd International Conference on Sustainable Future for Human Security (SUSTAIN 2012), 17, $408-417$.

Chapin, F. S., Kaiser, E. J. \& Godschalk, D. R. (1995), Urban land use planning, University of Illinois Press, 43-51. 
Cengiz, K., Ufuk, C. \& Ziya, U. (2003), Multi-criteria supplier selection using fuzzy AHP, Logistics Information Management, 6(16), 389-394.

European Commission (2002), Consultative guidelines for sustainable urban development co-operation. Towards sustainable urban development: A strategic approach, Document Report.

Finco, A. \& Nijkamp, P. (2001), Pathway to urban sustainability, Journal of Environmental Policy and Planning. 3(4), 289-302.

Gharagozlu, A. \& Barzegar, M. (2008), Ideal planning using AHP approach in order to optimization of production. Barasiha-ye Bazargani (text in Persian), 29, 59-72.

Guzmán, P. C., Pereira Roders, A. R. \& Colenbrander, B. J. F. (2017), Measuring links between cultural heritage management and sustainable urban development: An overview of global monitoring tools, Cities 60, 192-201.

Gilmour, D., Blackwood, D., Banks, L. \& Wilson, F. (2011), Sustainable development indicators for major infrastructure projects, Proceedings of the Institution of Civil EngineersMunicipal Engineer, 164(1), 15-24

Haughton, G. \& Hunter, C. (2003), Sustainable cities, Routledge: Taylor \& Francis group, London and New York.

Jepson, E. \& Haines, A. (2014), Zoning for sustainability: A review and analysis of the zoning ordinances of 32 cities in the United States, American Planning Association, 80(3), 239-252.

Jiboye, A. (2011), Sustainable urbanization: Issue and challenges for effective urban governance in Nigeria, Journal of Sustainable Development, 4(6), 211-224.

Jiboye, A. \& Omoniyi, S. (2010), Environmental sustainability and urban growth in Nigeria, Journal of Environmental Research and Policies, 5(1), 43-50.

Jiboye, A. \& Ogunshakin, L. (2011), Urban growth challenges in Nigeria: Implications for environment sustainability, British Journal of Humanities and Social Sciences, 1(2), 16-27.

Kam Ng, M. (2015), Editorial: The right to healthy placemaking and well-being, Planning Theory \& Practice, 17(1), 3-6.

Kashefidust, D. \& Hajinejad, A. (2015), The evaluation of urban land use approach to sustainable development (Case: Piranshahr city), Town and Country Planning (text in Persian), 7(1), 71-94

Mahdizade, J. (2005), The status of cultural heritages in urban sustainable development, Journal of jostarha-ye-shahrsazi (text in Persian), 12, 14-25.

Mohareb, N. (2010), Land use distribution as a sustainable indicator in Arab cities, Proceedings of the Institution of Civil Engineers - Urban Design and Planning, 163(3), 105-116.

Mukomo, S. (1996), On sustainable urban development in subSaharan Africa, Cities 13(4), 265-271Roseland, M. (1997), Dimension of the eco-city, Cities, 14(4), 197-202.

MÜLLER-EIE, D. \& BJØRNØ, L. (2017), The implementation of urban sustainability strategies: Theoretical and methodological implications for researching behavior change, International Journal of Sustainable Development and Planning, 12(5), 894-907.

Murgante, B., Borruso, G. \& Lapucci, A. (2009), (eds), Geocomputation and Urban Planning, First chapter of the studies in computational intelligence, Springer-Verlag Berlin Heidelberg, 176, 1-17.
Ogu, V. (1999), Evolutionary dynamics of urban land use planning and environmental sustainability in Nigeria, Planning perspectives, 14(4), 347-368.

Qian, J., Peng, Y., Luo, C., Wu, C. \& Du, Q. (2015), Urban land expansion and sustainable land use policy in Shenzhen: A case study of China's rapid urbanization, Sustainability, 8(1):16.

Roy, M. (2009), Planning for sustainable urbanization in fast growing cities: mitigation and adaption issues addressed in Dhaka, Bangladesh, Habitat International, 33, 276-286.

Sang, X., Chang, K., Yang, L. \& Scheffran, J. (2016), Change in environmental benefits of urban land use and its drivers in Chinese cities, 2000-2010, International Journal of Environmental Research and Public Health, 13(6), 535.

Shaker, R. R. \& Sirodoev, I. G. (2016), Assessing sustainable development across Moldova using household and property composition indicators, Habitat International. 55, 192-204.

Sofeska, E. (2016), Relevant factors in urban sustainable development of urban planning methodology and implementation of concepts for sustainable planning (Planning for documentation for the master plan Skopje 2001-2020), Procedia Environmental Sciences, 34, 140 - 151.

Timothee, P. (2010), Nicolas, L-B., Emanuele, S., Sergio, P. \& Stephane, J., A network based kernel density estimator applied to Barcelona economic activities, International Conference on Computational Science and Its Applications (ICCSA), 32-45.

Tweed, C. \& Sutherland, M. (2007), Built cultural heritage and sustainable urban development, Landscape and Urban Planning, 83(1), 62-69.

UN-Habitat (2009), Planning sustainable cities: policy directions, global report on human settlements (A bridged Edition), London: Earthscan.

United Nations (UN), Resolution adopted by the General Assembly (Seventieth session on 25 September 2015), Transforming our world: the 2030 Agenda for Sustainable Development,

http://www.un.org/ga/search/view_doc.asp?symbol=A/RES/70/ 1\&Lang=E, 2015.

WCED (1987), Report of the World Commission on Environment and Development: Our Common Future. http://www.un-documents.net/wced-ocf.htm.

Whitaker, R. (2007), Validation examples of the Analytic Hierarchy Process and Analytic Network Process, Mathematical and Computer Modelling, 46(7-8), 840-859.

World Bank (2010), Eco2 Cities: Ecological Cities as Economic Cities, P. 384

Yang, B., Xu, T. \& Shi, L. (2017), Analysis on sustainable urban development levels and trends in China's cities, Cleaner Production 141, 868-880.

Yigitcanlar, T \& Dizdaroglu, D. (2015), Ecological approaches in planning for sustainable cities A review of the literature, Global Journal of Environmental Science and Management, $1(2), 159-188$

Zhang, H., Uwasu, M., Hara, K. \& Yabar, H. (2011), Sustainable urban development and land use change- A case study of the Yangtze river delta in China, Sustainability, 3, 1074-1089.

Zebardast, E. (2001), The function of analytic hierarchy process in urban and regional planning. Honar-ha-ye Ziba (text in Persian), 10, 13-21. 